Limnol. Oceanogr., 46(2), 2001, 248-259

(C) 2001, by the American Society of Limnology and Oceanography, Inc.

\title{
Fine-scale measurement of diffusivity in a microbial mat with nuclear magnetic resonance imaging
}

\author{
Andrea Wieland ${ }^{1}$ and Dirk de Beer
}

Max Planck Institute for Marine Microbiology, Microsensor Research Group, Celsiusstrasse 1, D-28359 Bremen, Germany

\section{Lars R. Damgaard}

Department of Microbial Ecology, Institute of Biological Sciences, University of Aarhus, B.540 Ny Munkegade, DK-8000 Aarhus C, Denmark

\section{Michael Kühl}

Marine Biological Laboratory, University of Copenhagen, Strandpromenaden 5, DK-3000 Helsingør, Denmark

\section{Dagmar van Dusschoten ${ }^{2}$ and Henk Van As}

Laboratory of Molecular Physics and Wageningen NMR Center, Wageningen University, Dreijenlaan 3, NL-6703 HA Wageningen, The Netherlands

\begin{abstract}
Noninvasive ${ }^{1} \mathrm{H}$-nuclear magnetic resonance (NMR) imaging was used to investigate the diffusive properties of microbial mats in two dimensions. Pulsed field gradient NMR was used to acquire images of the $\mathrm{H}_{2} \mathrm{O}$ diffusion coefficient, $D_{s}$, and multiecho imaging NMR was used to obtain images of the water density in two structurally different microbial mats sampled from Solar Lake (Egypt). We found a pronounced lateral and vertical variability of both water density and water diffusion coefficient, correlated with the laminated and heterogeneous distribution of microbial cells and exopolymers within the mats. The average water density varied from 0.5 to 0.9 , whereas the average water diffusion coefficient ranged from 0.4 to 0.9 relative to the values obtained in the stagnant water above the mat samples. The apparent water diffusivities estimated from NMR imaging compared well to apparent $\mathrm{O}_{2}$ diffusivities measured with a diffusivity microsensor. Analysis of measured $\mathrm{O}_{2}$ concentration profiles with a diffusion-reaction model showed that both the magnitude of calculated rates and the depth distribution of calculated $\mathrm{O}_{2}$ consumption/production zones changed when the observed variations of diffusivity were taken into account. With NMR imaging, diffusivity can be determined at high spatial resolution, which can resolve inherent lateral and vertical heterogeneities found in most natural benthic systems.
\end{abstract}

Diffusion is the predominant mode of solute mass transfer between bacteria and their surroundings and is also the major mechanism of solute transport in impermeable sediments,

\footnotetext{
${ }^{1}$ Present address: Marine Biological Laboratory, University of Copenhagen, Strandpromenaden 5, DK-3000 Helsingør, Denmark.

${ }^{2}$ Present address: Max Planck Institute for Polymer Research, Ackermannweg 10, D-55021 Mainz, Germany.

\section{Acknowledgments}

The NMR measurements were performed at the EU large-scale NMR facility in Wageningen (grant ERBFMGECT950066). This study was supported by the German Ministry of Education and Research (BMBF; Red Sea Program on Marine Sciences, Project E: Microbial activities in marine interfaces controlling sediment-water fluxes), and the Max Planck Society. Gaby Eickert, Anja Eggers, and Vera Hübner are thanked for the construction of the $\mathrm{O}_{2}$ microsensors. The Interuniversity Institute in Eilat (Israel) is thanked for providing laboratory facilities. Yehuda Cohen is thanked for arranging the logistics of the Solar Lake field trip and for his support in Israel. The Egyptian authorities are thanked for their permission to work at Solar Lake. A.W. acknowledges the help from Bettina König with IDL and the fruitful discussions with Peter Berg. L.R.D. acknowledges the support by the EU (project MicroFlow MAS970078). M.K. acknowledges the support by the Danish Natural Science Research Council.
}

biofilms, and microbial mats. Knowledge about the diffusive properties is key information for quantification of biogeochemical processes and their regulation in benthic microbial communities (Berner 1980; Boudreau 1997).

Owing to their high spatiotemporal resolution and minimal disturbance, microsensors are almost ideal tools for characterizing physicochemical microenvironments and the steep gradients of solute concentration within biofilms and sediments (Revsbech and Jørgensen 1986; Amann and Kühl 1998). From measured concentration profiles, diffusive fluxes of solutes and the depth distribution and magnitude of process rates, i.e., net production/consumption of the diffusing chemical species, can be calculated via profile analysis based on diffusion-reaction models (e.g., Revsbech et al. 1986; Nielsen et al. 1990; Rasmussen and Jørgensen 1992; Epping and Jørgensen 1996; Berg et al. 1998; Kühl et al. 1998).

However, a precise analysis of microsensor data depends on fine-scale measurements of the apparent diffusivity, $D_{\text {app }}$, of the solute in the system (Revsbech et al. 1986; Revsbech 1989a; Glud et al. 1995). The presence of impermeable particles causes an increase of the diffusional pathlength by steric hindrance, referred to as the geometric tortuosity, $\theta$, resulting in a lower solute diffusion coefficient in the sedi- 
ment, $D_{s}$, as compared to the free solution molecular diffusion coefficient, $D_{0}$, which is expressed by (Berner 1980):

$$
D_{s}=D_{0} \theta^{-2} \text {. }
$$

Furthermore, in sediments the porosity, $\phi$, and thus the volume available for diffusion, is reduced, and therefore

$$
D_{\text {app }}=\phi D_{0} \theta^{-2} \text {. }
$$

Using inert tracers or biologically inactivated sediment samples, $D_{s}$ can be determined with transient methods, e.g., by following the equilibration of the system after an instantaneous concentration change in the overlying bulk liquid (e.g., Duursma and Bosch 1970). $D_{s}$ can then be calculated from the time-dependent increase of the tracer concentration at different depths of the sample, as measured with, e.g., microsensors (Revsbech et al. 1986; Cronenberg and Van den Heuvel 1991; Beuling 1998).

The apparent diffusivity, $D_{\text {app }}$, can either be calculated from $D_{s}$ if the porosity is known, or directly be determined from measured steady-state concentration profiles in the sediment and Fick's first law of diffusion: $J=D_{\text {app }} d C / d x$. In steady state, the flux $J$ is constant through all layers of the matrix, and if no conversion of the solute is taking place changes in the slope $(d C / d x)$ of the profile are caused only by variations of $D_{\text {app. }}$. Also for this approach, inert tracers or biologically inactivated samples must be used, and the sample has to be equilibrated in a diffusion chamber (Revsbech 1989a; Glud et al. 1995). The latter was recently overcome by the development of a novel microsensor for determination of $D_{\text {app, }}$, which is based on the continuous detection of the diffusion of an inert tracer gas away from the sensor tip (Revsbech et al. 1998). However, even with this diffusivity microsensor, we can only address the diffusive properties of complex natural samples from a relatively limited number of point measurements.

In translucent biofilms, confocal microscopy has been used for determining diffusivity with high spatial resolution (de Beer et al. 1997). This method is, however, not directly applicable in sediments and optically dense biofilms and microbial mats.

In the present study, we used an alternative approach to determine $D_{s}$ at a high spatial resolution in intact and biologically active samples by using $\mathrm{H}_{2} \mathrm{O}$ as a tracer in combination with noninvasive ${ }^{1} \mathrm{H}$-nuclear magnetic resonance (NMR) imaging. By this method, two-dimensional distributions of the water diffusion coefficient and the water density (see below) in stratified microbial mats were obtained for the first time.

NMR measurements are based on the magnetic moment (spin) of certain nuclei, e.g., ${ }^{1} \mathrm{H}$. When a sample containing these nuclei is placed in an external magnetic field, $B_{0}$, a macroscopic magnetization results from the alignment of the spins in the direction of $B_{0}$. This magnetization can be detected by application of a short radio frequency pulse with a characteristic NMR resonance frequency (characteristic for a particular nucleus at a particular $B_{0}$ ). After excitation, the amplitude of this NMR signal decays as a function of time, which can be measured by generating so-called spin echoes. The NMR signals and their decay are characterized by different parameters from which several characteristics of the sample can be derived: the initial amplitude, $A_{0}$, of the NMR signal immediately after excitation is a measure of the amount (density) of nuclei in the sample. Two relaxation time constants $\left(T_{1}, T_{2}\right)$ describe the return of the spin system to equilibrium from which several physical characteristics of the sample can be derived (as a review for porous [bio]systems see Van As and van Dusschoten 1997).

Molecular diffusion of spin carrying molecules like $\mathrm{H}_{2} \mathrm{O}$ can be measured with $\left({ }^{1} \mathrm{H}\right)$ NMR if additionally pulsed magnetic field gradients (PFG) are applied (Stejskal and Tanner 1965). Random displacement (diffusion) of spin carrying molecules in the presence of magnetic field gradients results in an attenuation of the NMR signal amplitude from which the diffusion constants of these molecules in the sample can be calculated.

Spatially resolved information is obtained by application of NMR imaging (MRI, for details and review see Morris 1986; Moonen et al. 1990; Van As and van Dusschoten 1997). Images of slices through the sample can be achieved if the NMR signal after excitation is acquired in the presence of linear magnetic field gradients. An image consists of $N$ $\times N$ (here $128 \times 128)$ picture elements, so-called pixels. Single parameter images of, e.g., the nucleus density (amount of nuclei per pixel of defined volume) and diffusion coefficient can be obtained on a pixel by pixel basis (van Dusschoten et al. 1996; Van As and van Dusschoten 1997; Edzes et al. 1998).

\section{Materials and methods}

NMR imaging — A Surrey medical imaging system (SMIS, Guildford) imager was used for NMR experiments. The SMIS imager is equipped with an electromagnet (Bruker) that generates a $0.47 \mathrm{~T}$ magnetic field, resulting in a ${ }^{1} \mathrm{H}$ resonance frequency of $20.35 \mathrm{MHz}$. A microscopy probe (Doty Scientific) containing a solenoidal radio frequency coil (length and diameter $45 \mathrm{~mm}$ ), which is surrounded by a set of actively shielded gradients, was fitted in the 0.14-m air gap of the magnet. A Plexiglas core tube of ca. $2.6 \mathrm{~cm}$ inner diameter containing the mat sample was positioned in the probe bore (4.5 $\mathrm{cm}$ diameter), which was accessible from both ends. Custom-written pulse programs in SMIS language were used.

To obtain images of the $\mathrm{H}_{2} \mathrm{O}$ diffusion constants in mat samples, i.e., $D_{s}$, we used either a so-called pulsed field gradient Carr-Purcell-Meiboom-Gill (PFG CPMG) sequence (van Dusschoten et al. 1996) or a pulsed field gradient turbo spin echo (PFG TSE) sequence (Scheenen et al. 1998). The PFG CPMG sequence enables the simultaneous determination of $A_{0}, T_{2}$, and diffusion at a set of echo times (van Dusschoten et al. 1996), but one NMR imaging experiment in microbial mats takes about 2-3 h (usually consisting of 128 imaging steps $\times 8$ pulsed field gradients steps $\times 2-8$ averaging steps at a repetition time $T R$ ). The use of the PFG TSE sequence reduced the measuring time to $0.5-1 \mathrm{~h}$ in microbial mats.

During one set of experiments, diffusion measurements were repeated eight times at increasing $G$ (amplitude of the pulsed field gradient) using either the PFG CPMG or the 
PFG TSE sequence. The magnetic field gradients were increased up to $500 \mathrm{mT} \mathrm{m}^{-1}$. All measurements were performed at room temperature $\left(24-25^{\circ} \mathrm{C}\right)$. The acquired sets of images were analyzed on a pixel by pixel basis. From the PFG CPMG experiment a two-dimensional data set per pixel (as a function of time and $G$ ) was obtained, and the (decay of the) signal amplitude at time $T E$ can be described by

$$
A(T E, b)=A_{0} \exp \left(-T E / T_{2}\right) \exp (-b D)
$$

with

$$
b=\gamma^{2} \delta^{2} G^{2}(\Delta-\delta / 3),
$$

where $\gamma$ is the gyromagnetic ratio, a constant specific for each type of nucleus, that determines the resonance frequency in a given magnet field. $\Delta$ is the time between the pulsed field gradients and $\delta$ is the duration of the pulse.

The data were analyzed with a two-dimensional nonlinear least square (NLLS) fitting routine based on the MarquardtLevenberg algorithm (Press et al. 1992). Using this twodimensional fitting routine, the data were fitted to Eq. 3, assuming that molecules within one pixel element experienced a similar physical environment (see van Dusschoten et al. 1996). The set of images obtained from the PFG TSE experiment was analyzed by fitting the data (in each pixel) to an equation describing the decay of the signal amplitude (as a function of diffusion, see second part of Eq. 3) using a standard one-dimensional NLLS fitting routine based on the Marquardt-Levenberg algorithm (Press et al. 1992). The fitting routines were programmed using IDL (interactive data language, Research Systems).

Images of the amplitude $A_{0}$ were obtained each time in separate experiments by multiecho imaging (Edzes et al. 1998). The duration of each experiment was ca. $2 \mathrm{~h}$. The signal intensity in each pixel in the successive images was fitted as a monoexponential decay (cf. first part of Eq. 3) with a one-dimensional NLLS fitting routine (see above). Real spin-density images $\left(A_{0}\right)$ were obtained by extrapolation of the amplitude images to time $T E=0$ (see Van As and van Dusschoten 1997; Edzes et al. 1998), yielding images of water density (amount of water per pixel of defined volume). The normalized mat water density (see below) was used as an estimate of the mat porosity.

The dimensions of the acquired images are given by the field of view, i.e., the dimension for each axis in the plane, and the slice thickness, which represents the plane thickness. All images consisted of $128 \times 128$ pixels with a field of view of $30 \mathrm{~mm}$, resulting in a resolution of $234 \mu \mathrm{m}$ per pixel. Further details on instrument settings are given in the figure legends. For the diffusion measurements, the pulsed field gradients were applied perpendicular to the mat surface, which is the direction in which diffusion was measured.

Values of $D_{s}$ and water density were extracted from the data matrices obtained in the different NMR experiments. We used only those values of $D_{s}$ in the data matrix that were (1) greater than zero, (2) greater than their standard deviation, (3) lower than the values obtained in the overlying water, and (4) with an amplitude greater than the background (noise) level, as estimated, e.g., from the region of the Plexiglas tube where no water or proton signal was observed (not included in the extracted images shown in Figs. 1 and
3). Data that did not fulfill these criteria were set to zero (dark black zones). Similar criteria were used to sort the data of water density. Only values $>0$ were included in the depth profiles of these parameters. To mimic the situation in the flow chamber during microsensor measurements, we created a minor flow in the overlying water during the NMR experiment in the April mat (see below) by a gentle air stream over the water surface. The obtained data of $D_{s}$ and water density in the mat were normalized to values of stagnant water within the core tube, which is, for simplicity, in the following referred to as overlying water. During the measurements in the November mat sample (see below), we did not create a flow in the overlying water, and values of $D_{s}$ and water density in the mat were normalized to the values in the overlying water. The diffusion measurements (PFG TSE) resulted in a relatively low signal to noise ratio (see Results). For data analysis most of these high noise signals (white spots in the image) were not considered, resulting in a reduction of available data for the calculation of $D_{s}$.

Mat samples-Mat samples were collected in April and November 1997 in the shallow eastern part of Solar Lake (Sinai, Egypt). The in situ temperature and salinity were $28^{\circ} \mathrm{C}$ and $86 \%$ in April and $30^{\circ} \mathrm{C}$ and $83 \%$ in November. The mat samples were transported within a few hours after sampling to the Interuniversity Institute in Eilat (Israel), where $\mathrm{O}_{2}$ microsensor measurements were performed in a laboratory. The 2- to 3-mm thick gelatinous golden brownish surface layer of the April mat was composed of diatoms (Navicula sp., Nitzschia sp.) and unicellular cyanobacteria belonging to the Halothece cluster (Garcia-Pichel et al. 1998). Below this surface layer, a ca. 0.5-mm thick green layer of filamentous cyanobacteria (mainly Microcoleus chthonoplastes) was found. In the November sample, a ca. 0.5 - to 1-mm thick dark green cohesive surface layer composed of filamentous cyanobacteria (mainly M. chthonoplastes) was found at the mat surface.

After the microsensor measurements in Eilat, the mat samples were transferred to the MPI Bremen, where they were stored for 1 to 3 weeks in aerated brine in light, prior to the experiments at the EU large-scale NMR facility in Wageningen (Netherlands). During this time interval, the mat samples did not undergo a significant change in structure and macroscopic appearance as compared to the mat samples in Eilat.

Oxygen microsensor measurements-Mat subsamples were taken with Plexiglas core tubes with an inner diameter of 5.0 to $5.6 \mathrm{~cm}$ (April). The core tube was fixed in a flow chamber modified from Lorenzen et al. (1995). In November, a mat subsample (approximately $5 \times 4 \times 2 \mathrm{~cm}$ ) was embedded in agar (1.5\% in Solar Lake water) in a similar flow chamber.

Clark-type $\mathrm{O}_{2}$ microelectrodes (Revsbech 1989b), with outer tip diameters of $<10 \mu \mathrm{m}$ and stirring sensitivities of $<1-2 \%$, were used to measure depth profiles of $\mathrm{O}_{2}$. The $\mathrm{O}_{2}$ microelectrodes were calibrated from readings in the aerated overlying Solar Lake water (100\% air saturation) and in the anoxic part of the mat ( $0 \%$ oxygen). Dissolved $\mathrm{O}_{2}$ concentrations in aerated Solar Lake brine at experimental temper- 

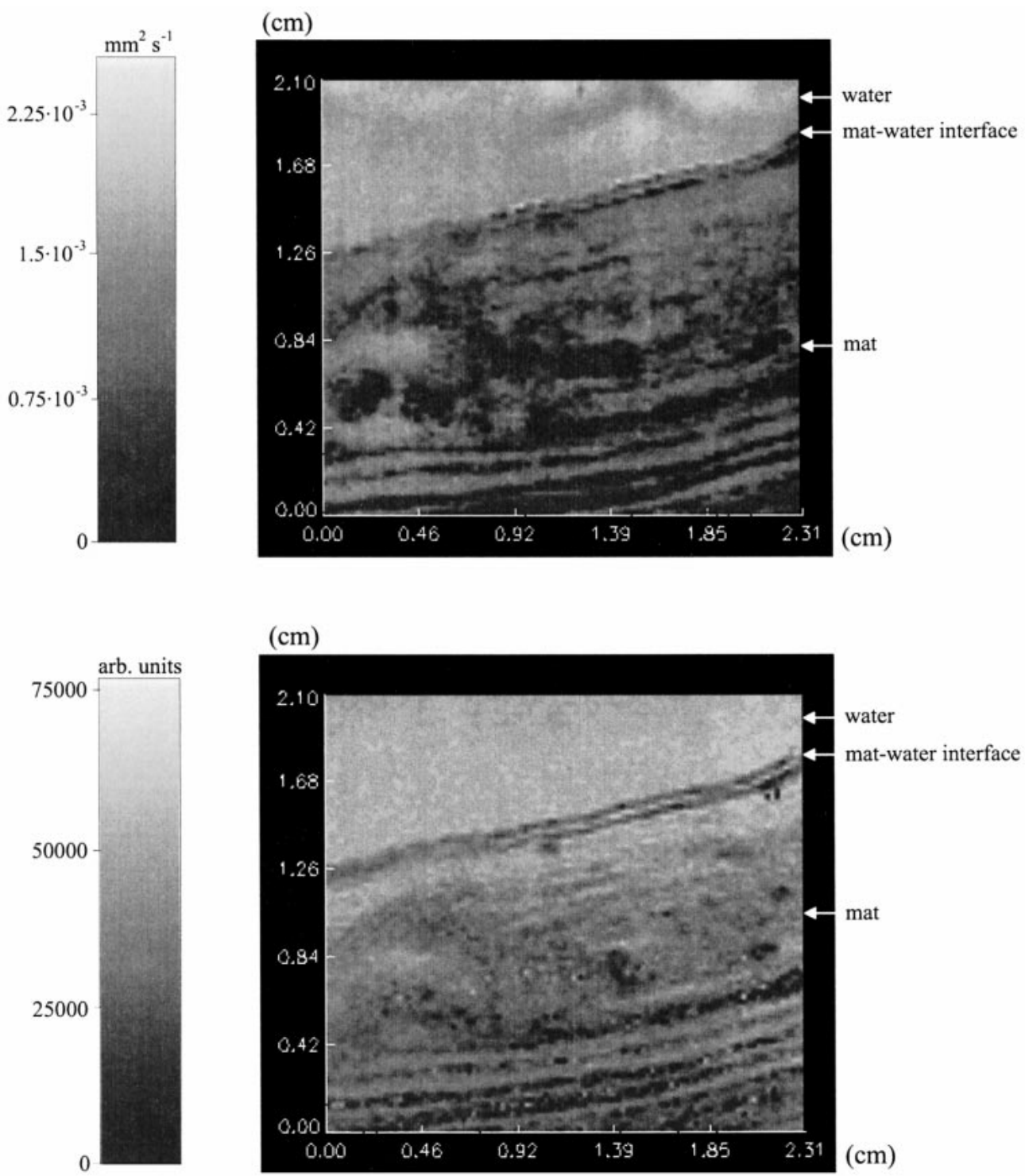

Fig. 1. Upper image: Image of the $\mathrm{H}_{2} \mathrm{O}$ diffusion constant in a cyanobacterial mat (from April) measured with the PFG CPMG sequence. Lower image: Image of the water density (amplitude $A_{0}$ ) measured in the same sample by multiecho imaging. The framing scale indicates the size $(\mathrm{cm})$ of the mat slice imaged. The scale bars relate the darkness scale to values of diffusion coefficient $\left(\mathrm{mm}^{2} \mathrm{~s}^{-1}\right)$ and water density (arbitrary units). Parameters (upper image): $\Delta=16.6 \mathrm{~ms}, \delta=3.5 \mathrm{~ms}$, $T E=21+n 6.6 \mathrm{~ms}(n=0-15), T R=3.5 \mathrm{~s}, 16$ echoes (per sequence), slice thickness $=2.5 \mathrm{~mm}$. Parameters (lower image): $T E=21+n 4.2 \mathrm{~ms}, T R=9 \mathrm{~s}, 24$ echoes, slice thickness $=2.5 \mathrm{~mm}$.

atures and salinities were calculated according to Sherwood et al. (1991). More details concerning the experimental setup and the $\mathrm{O}_{2}$ microsensor measurements are given in Wieland and Kühl $(2000 a, b)$.

Measurements in November were performed at room temperature $\left(26^{\circ} \mathrm{C}\right)$ and $957 \mu \mathrm{mol}$ photons $\mathrm{m}^{-2} \mathrm{~s}^{-1}$, whereas in April the downwelling surface irradiance was $626 \mu \mathrm{mol}$ photons $\mathrm{m}^{-2} \mathrm{~s}^{-1}$ and the water temperature was adjusted to $30^{\circ} \mathrm{C}$ with a heat exchanging metal coil connected to a thermostat (Julabo).

Diffusivity microsensor measurements - The apparent diffusivity, $\phi D_{s}$, was measured in a Solar Lake mat with a diffusivity microsensor (Revsbech et al. 1998) using acetylene as the tracer gas. The diffusivity microsensor had an outer tip diameter of $60 \mu \mathrm{m}$. The Solar Lake mat was sampled in December 1998 and was stored aerated and illuminated prior to the diffusivity microsensor measurements. The mat sample had a similar structure and composition as the mat sample from November 1997 (see above). Diffusivity microsensor measurements were performed at room temperature $\left(24^{\circ} \mathrm{C}\right)$ in a mat subsample, taken with a Plexiglas core tube of ca. $2.6 \mathrm{~cm}$ inner diameter. The mat subsample was covered by stagnant artificial seawater $(95 \%)$ ). The apparent diffusivity in the mat was measured in steps of $250-\mu \mathrm{m}$ vertical depth intervals. The microsensor was calibrated from 

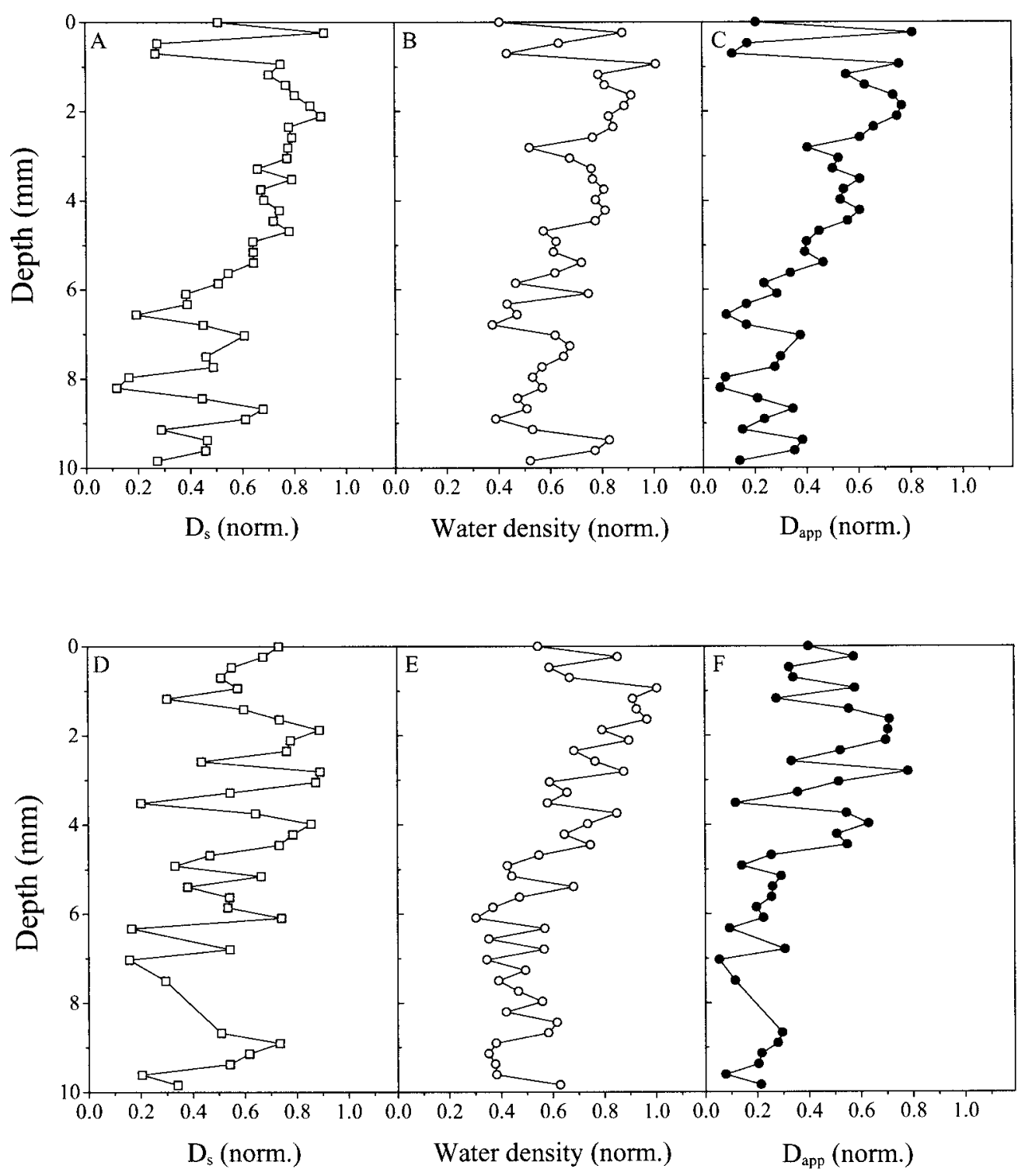

Fig. 2. Depth profiles of the normalized $D_{s}$, water density, and $D_{\text {app }}$ at two different positions in the April mat $\left(D_{s}\right.$ and water density profiles were extracted from the images shown in Fig. 1). Upper panel shows the parameters at the first position $(\mathrm{A}-\mathrm{C})$, lower panel at the second position (D-F). The mat surface is located at depth 0 on the depth axis and increasing numbers on the axis show the corresponding increasing depths within the mat.

signal readings in artificial seawater of experimental temperature and salinity and from readings in 40-60- $\mu \mathrm{m}$ glass beads with a known apparent diffusivity of oxygen (Revsbech et al. 1998). It was assumed that relative changes of apparent diffusivity between different media were identical for oxygen and acetylene. The acetylene sensor is sensitive to $\mathrm{H}_{2} \mathrm{~S}$, which was abundant below 1 to $2 \mathrm{~mm}$ depth in the mats (data not shown). The $\mathrm{H}_{2} \mathrm{~S}$ interference was minimized by using a high $(100 \%)$ acetylene concentration in the diffusivity sensor reservoir, and the measured data were corrected for the remaining $\mathrm{H}_{2} \mathrm{~S}$ interference by the following procedure: $\mathrm{H}_{2} \mathrm{~S}$ concentration profiles were measured in the Solar Lake mat with a $\mathrm{H}_{2} \mathrm{~S}$ microsensor (Jeroschewski et al. 1996; Kühl et al. 1998) and $\mathrm{a}_{2} \mathrm{~S}$ calibration was performed on the diffusivity sensor in stagnant water of the same temperature and salinity as in the mats. During data processing, the calculated $\mathrm{H}_{2} \mathrm{~S}$-induced signal was subtracted from the total diffusivity sensor signal before the signal was transformed into diffusivity units.

Calculations-Measured $\mathrm{O}_{2}$ concentration profiles were analyzed with a numerical procedure for the interpretation of steady-state microprofiles (Berg et al. 1998). This procedure is based on a series of least-square fits to measured concentration profiles, assuming an increasing number of production and consumption zones. The fits are compared by statistical $F$-testing, so that the simplest production/consumption profile results that reproduces the measured con- 

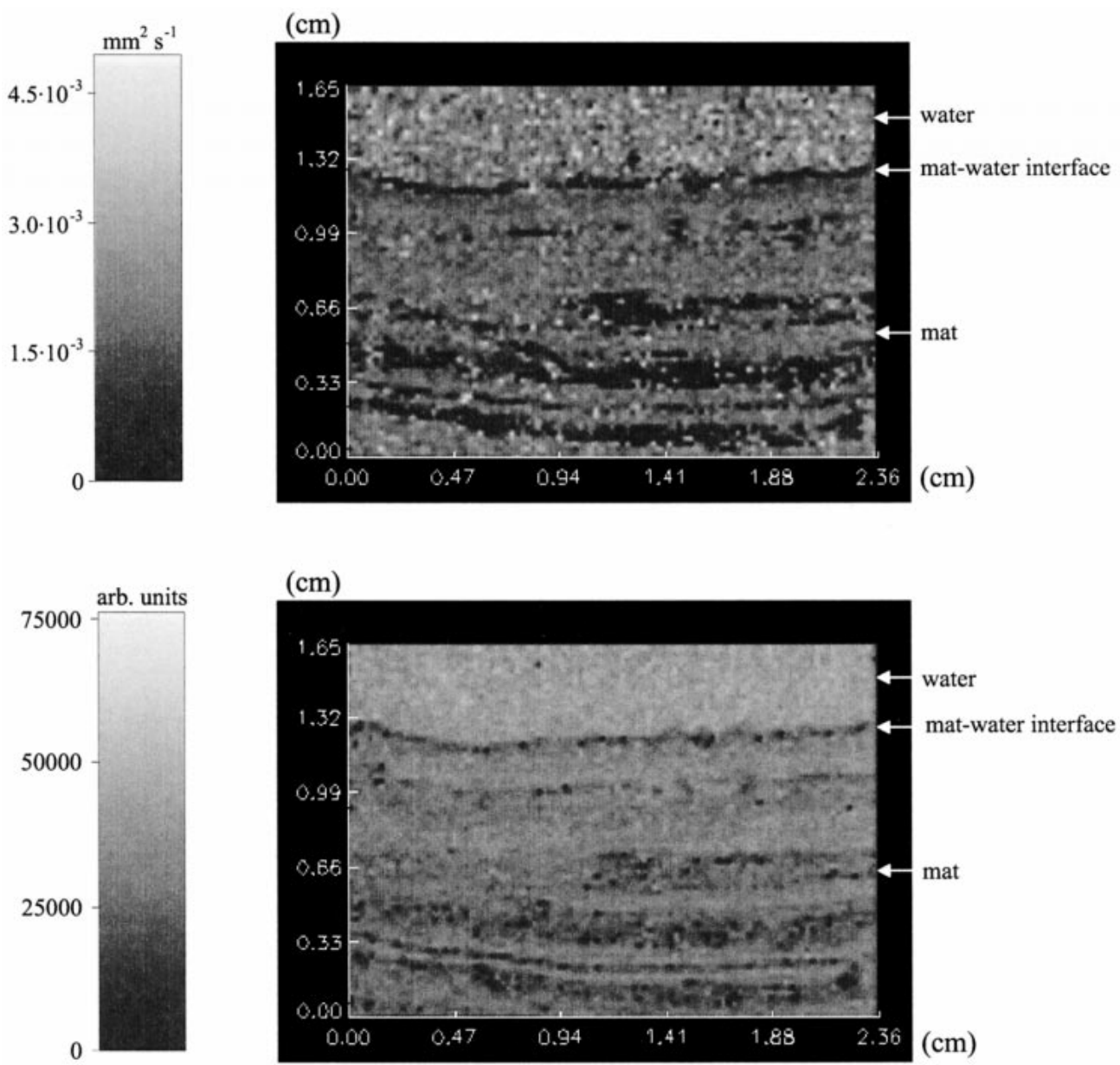

Fig. 3. Upper image: Image of the $\mathrm{H}_{2} \mathrm{O}$ diffusion constant in a cyanobacterial mat (from November) measured with the PFG TSE sequence. Lower image: Image of the water density (amplitude $A_{0}$ ) measured in the same sample by multiecho imaging. The framing scale indicates the size $(\mathrm{cm})$ of the mat slice imaged. The scale bars relate the darkness scale to values of diffusion coefficient $\left(\mathrm{mm}^{2} \mathrm{~s}^{-1}\right)$ and water density (arbitrary units). Parameters (upper image): $\Delta=7.9 \mathrm{~ms}, \delta=5.0 \mathrm{~ms}$, $T E=15+n 7.9 \mathrm{~ms}, T R=1.5 \mathrm{~s}, 16$ echoes, slice thickness $=2.2 \mathrm{~mm}$. Parameters (lower image); $T E=15+n 2.9 \mathrm{~ms}, T R=7.5 \mathrm{~s}, 32$ echoes, slice thickness $=2.2 \mathrm{~mm}$.

centration profile within the chosen statistical accuracy (Berg et al. 1998). The measured steady-state $\mathrm{O}_{2}$ concentration profiles were analyzed with this procedure by assuming a constant porosity of 0.9 (Jørgensen and Cohen 1977; Jørgensen et al. 1979) and a constant $D_{s}$, which was calculated as (Ullman and Aller 1982):

$$
D_{s}=\phi^{2} D_{0}
$$

where $D_{0}$ is the free solution molecular diffusion coefficient of $\mathrm{O}_{2}$, which was taken from Broecker and Peng (1974) and corrected for salinity and temperature ( $\mathrm{Li}$ and Gregory 1974). Profile analysis was also done with (1) the $D_{s}$ depth profiles obtained from the NMR measurements and a constant porosity of 0.9 (see above), and with (2) both the $D_{s}$ profiles and the profiles of water density $\left(A_{0}\right)$ measured in the NMR experiments. From the profile analysis, areal rates of net $\mathrm{O}_{2}$ production and consumption in the mats were calculated by multiplying the calculated (volumetric) rates by the thickness of the reaction zone and summing the different rates of production and consumption. The total areal net $\mathrm{O}_{2}$ production rate in light incubated mats was calculated as the difference between the depth-integrated net $\mathrm{O}_{2}$ production and consumption rates in the various reaction zones.

\section{Results}

NMR and diffusivity measurements-The NMR imaging experiments showed a pronounced vertical and horizontal heterogeneity of $D_{s}$ and water density and, therefore, of diffusivity in the microbial mats (Figs. 1 and 3). Despite a relatively low signal to noise ratio of the image of $D_{s}$ in the November mat (Fig. 3, upper image), alternating strata of high and low $D_{s}$ and water density were found with depth in both mats. As $D_{s}$ and water density covaried, a similar stratification of low and high apparent diffusivity was found (Fig. 5).

In the gelatinous mat sampled in April, a broad zone of relatively high water density and $D_{s}$ was present in the upper 

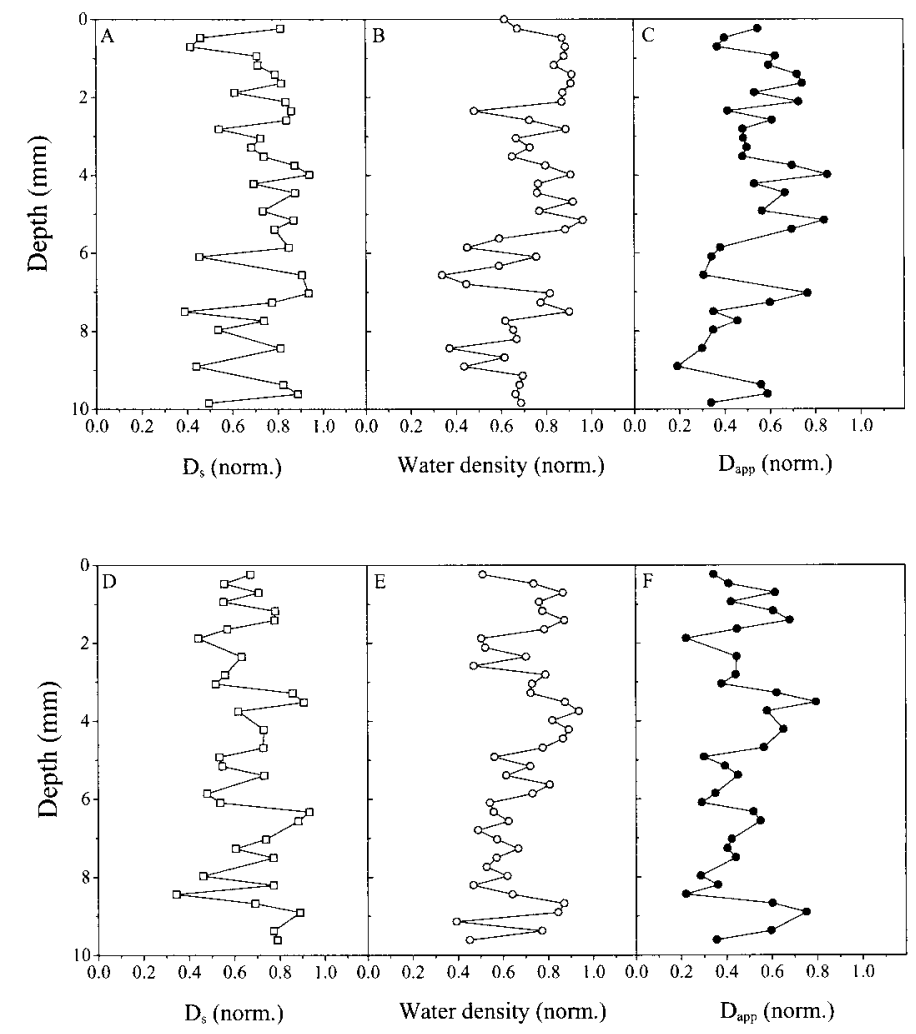

Fig. 4. Depth profiles of the normalized $D_{s}$, water density, and $D_{\text {app }}$ at two different positions in the November mat $\left(D_{s}\right.$ and water density profiles were extracted from the images shown in Fig. 3). Upper panel shows the parameters at the first position (A-C), lower panel at the second position (D-F). The mat surface is located at depth 0 on the depth axis and increasing numbers on the axis show the corresponding increasing depths within the mat.

$4 \mathrm{~mm}$ (Figs. 2, 5A,B). In deeper mat layers the water density and $D_{s}$ generally decreased (Fig. 5A,B), whereas in some areas of the mat a pattern of alternating high and low values of water density and $D_{s}$ was observed (Fig. 2A,B). In some areas of the mat surface, a sharp transition between low and high values of water density and $D_{s}$ occurred over the upper $\mathrm{mm}$ (Fig. 2A,B). The depth profiles of $D_{s}$ and water density at two different positions within the mat (Fig. 2) and the standard deviation of the horizontally averaged depth profiles (Fig. 5A,B) indicate both a pronounced vertical and horizontal variability of these parameters within the mat. Average values of water density and $D_{s}$ in the April mat varied from 0.48 to 0.88 and from 0.42 to 0.84 times the value in the overlying water. Average values of $D_{\text {app }}$ varied from 0.21 to 0.71 (Fig. 5A,B,C).

In the cohesive mat sampled in November, 1- to 2-mm thick bands of alternating high and low water density and $D_{s}$ were present throughout the mat (Figs. 4, 5D,E). The variability of water density, $D_{s}$, and, therefore, of diffusivity was less than in the April mat sample. Average values of water density and $D_{s}$ in the November mat varied from 0.54 to 0.86 and from 0.67 to 0.87 times the value in the overlying water, whereas the average values of $D_{\text {app }}$ varied from 0.38 to 0.71 (Fig. 5D,E,F).

The apparent $\mathrm{O}_{2}$ diffusivity was measured with a diffusiv-
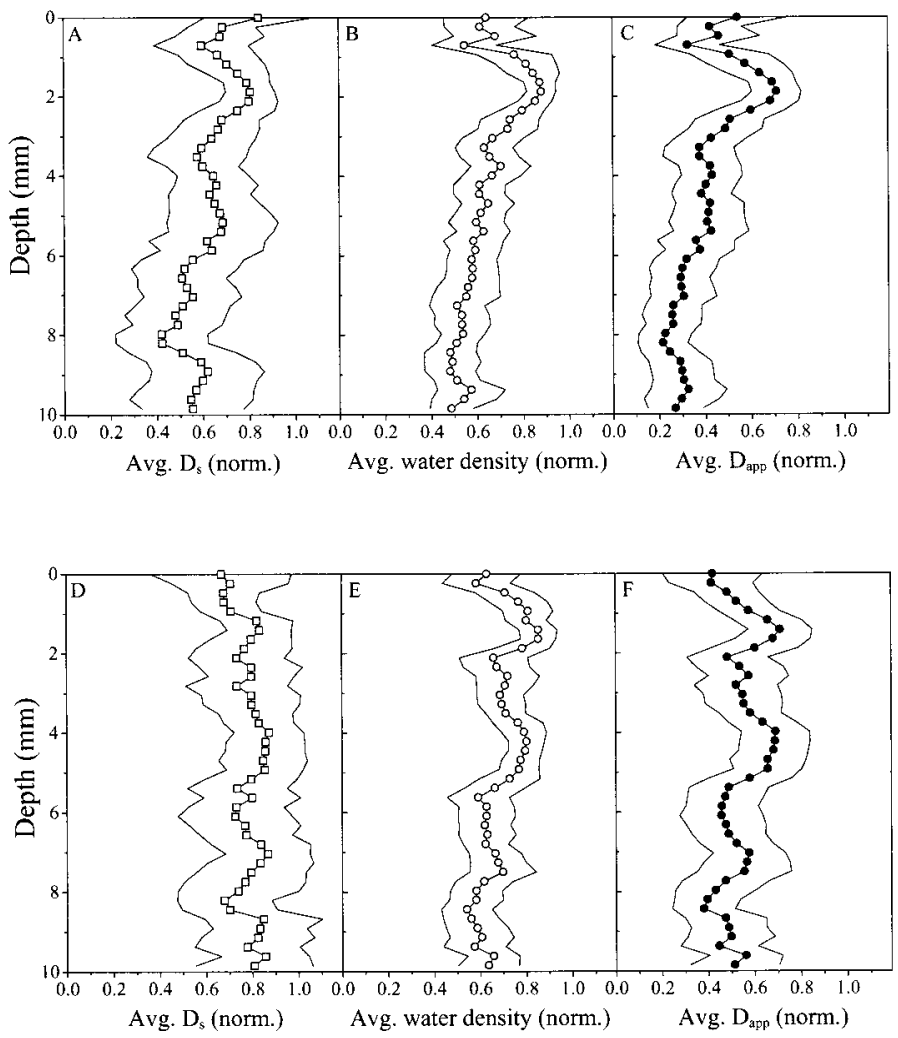

Fig. 5. Depth profiles of the average normalized $D_{s}$ ([A] April mat, [D] November mat), water density ([B] April mat, [E] November mat) and $D_{\text {app }}$ ([C] April mat, [F] November mat) obtained from the different NMR experiments. The line graphs show the depth distribution of the standard deviation. The mat surface is located at depth 0 on the depth axis and increasing numbers on the axis show the corresponding increasing depths within the mat.

ity microsensor in a Solar Lake mat sample from December 1998, which had a similar structure and composition to the November 1997 mat (Fig. 6A). In the uppermost ca. $1 \mathrm{~mm}$ of the mat, normalized $\mathrm{O}_{2}$ diffusivity varied between 0.6 and 0.85 and then approached a relatively stable value of ca. 0.6 with increasing depth. Compared to the diffusivity microsensor data, the diffusivity of $\mathrm{H}_{2} \mathrm{O}$, as determined from NMR measurements in the November mat (Fig. 6B), was lower in the upper $\mathrm{mm}$ and slightly higher 1 to $2 \mathrm{~mm}$ below the mat surface. In deeper layers, both profiles varied approximately around the same range of normalized diffusivities.

Oxygen microprofiles-With a numerical procedure (Berg et al. 1998), the rates of net $\mathrm{O}_{2}$ production/consumption in the mats were calculated from measured $\mathrm{O}_{2}$ concentration profiles. In the light incubated April mat, the oxic zone was 3.5-mm thick (Fig. 7). Besides a broad $\mathrm{O}_{2}$ peak in the surface layer, a second $\mathrm{O}_{2}$ peak at around 2.3 to $2.5 \mathrm{~mm}$ depth was observed. Assuming both a constant porosity and a constant $D_{s}$, two distinct zones of net $\mathrm{O}_{2}$ production in the upper layer of the mat were calculated, with the highest rate located in the surface layer (Fig. 7, dotted bars). A third zone of net $\mathrm{O}_{2}$ production was calculated at the depth of the indicated second $\mathrm{O}_{2}$ peak, which is separated from the other produc- 


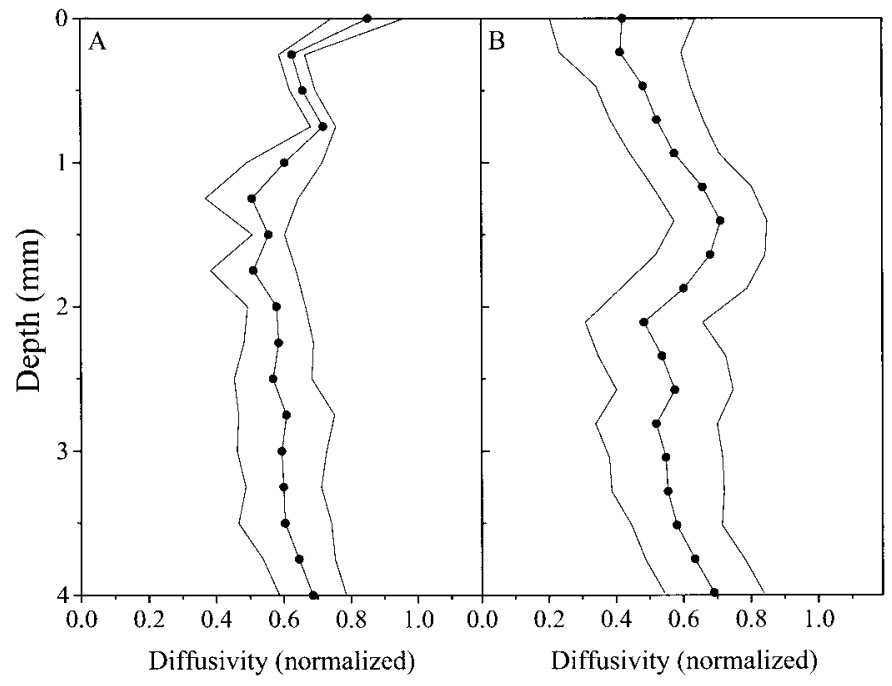

Fig. 6. (A) Averaged $(n=3)$ and normalized depth profile of apparent $\mathrm{O}_{2}$ diffusivity in a Solar Lake mat from December measured with a diffusivity microsensor. (B) Depth profile of the average normalized $D_{\text {app }}$ from the NMR experiments in the November mat. The standard deviation is shown as line graphs. The mat surface is located at depth 0 on the depth axis and increasing numbers on the axis show the corresponding increasing depths within the mat.

tion zones by a zone of net $\mathrm{O}_{2}$ consumption. A zone of low and a zone of high $\mathrm{O}_{2}$ consumption was calculated in the lower part of the oxic zone. Areal rates of $\mathrm{O}_{2}$ production and consumption amounted to $0.347 \mathrm{nmol} \mathrm{O}_{2} \mathrm{~cm}^{-2} \mathrm{~s}^{-1}$ and 0.121 nmol $\mathrm{O}_{2} \mathrm{~cm}^{-2} \mathrm{~s}^{-1}$, resulting in a total net production rate of $0.226 \mathrm{nmol} \mathrm{O}_{2} \mathrm{~cm}^{-2} \mathrm{~s}^{-1}$.

Profile analysis was repeated using (1) the average $D_{s}$ profile from the NMR measurements (Fig. 5A) and a constant porosity of 0.9 and (2) the average $D_{\text {app }}$ profile from the NMR measurements (Fig. 5C). Both analyses resulted in the same pattern (depth distribution) of net $\mathrm{O}_{2}$ production/consumption zones (data not shown) as compared to the one calculated assuming a constant diffusivity. However, the calculated rates in the different reaction zones changed when the variation of average $D_{s}$ and $D_{\text {app }}$ was taken into account, leading to a change of the magnitude of calculated areal net $\mathrm{O}_{2}$ production and consumption rates and therefore of the total areal net $\mathrm{O}_{2}$ production rate (Table 1).

Profile analysis was also done with the $D_{s}$ and $D_{\text {app }}$ profile from two different positions in the mat (Fig. 2). The $D_{\text {app }}$ profiles were calculated from the $D_{s}$ profiles and the water density profiles at approximately the same positions in the mat. In addition to the change of the magnitude of calculated rates (Table 1), these analyses resulted also in a change of the pattern (depth distribution) of calculated net $\mathrm{O}_{2}$ production/consumption zones (Fig. 7) as compared to the one calculated assuming a constant diffusivity (dotted bars).

In the November mat, the oxic zone was only $1.8-\mathrm{mm}$ thick with one distinct $\mathrm{O}_{2}$ peak in the surface layer (Fig. 8). Assuming a constant diffusivity for profile analysis, two net $\mathrm{O}_{2}$ production zones in the surface layer, with the highest rate located in the upper ca. $0.3 \mathrm{~mm}$, were calculated (Fig. 8 , dotted bars). Between these zones and the zone of net $\mathrm{O}_{2}$

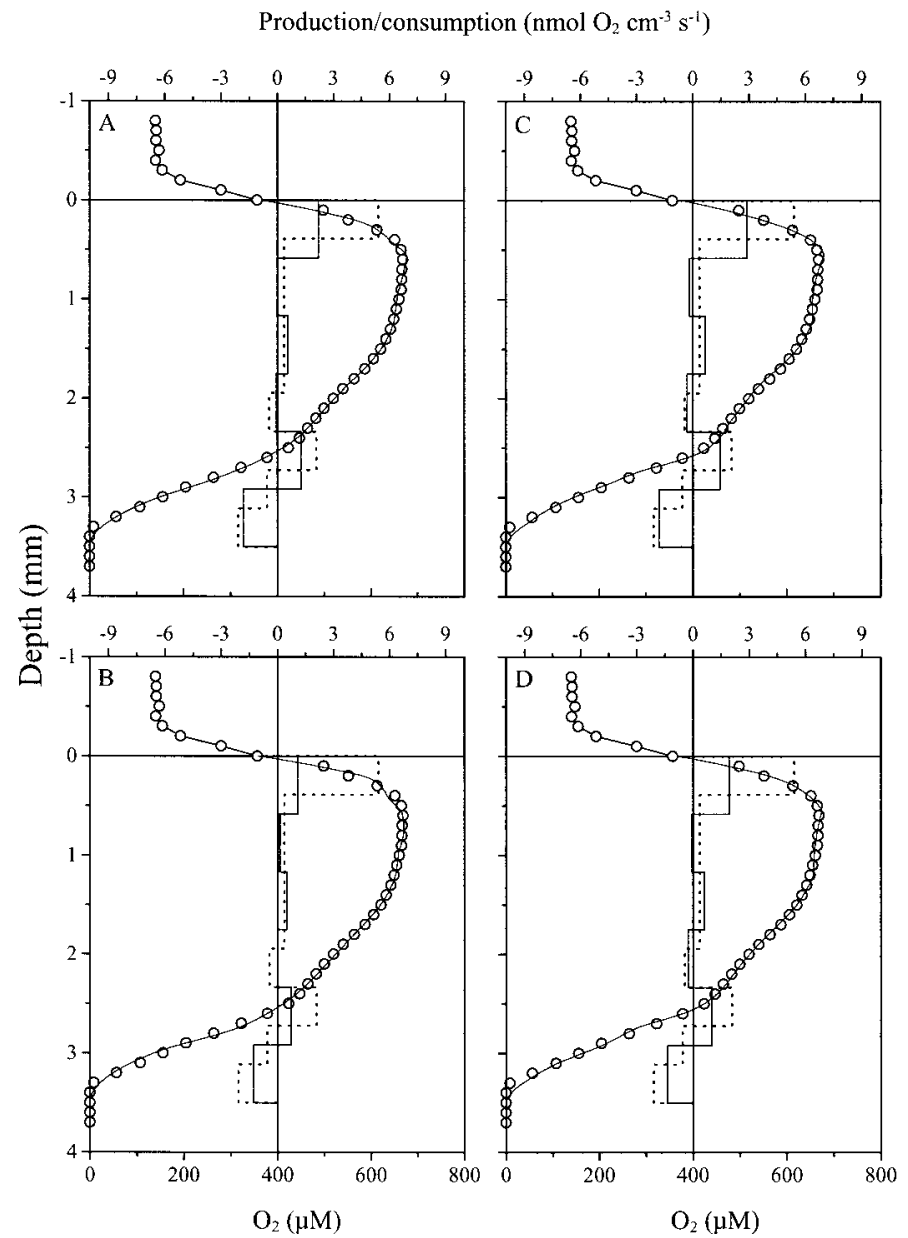

Fig. 7. Calculated depth profile of $\mathrm{O}_{2}$ production/consumption zones (bars) if (A) the $D_{s}$ profile and (B) the $D_{\text {app }}$ profile at the first position (Fig. 2A,C), and (C) the $D_{s}$ profile, and (D) the $D_{\text {app }}$ profile at the second position (Fig. 2D,F) in the April mat was used for profile analysis (see text). The dotted bars indicate the calculated reaction zones if a constant diffusivity is assumed. Open circles show the measured $\mathrm{O}_{2}$ concentration profile. The line graphs indicate the fitted profiles calculated by the numerical procedure (Berg et al. 1998). The mat surface is located at depth 0 on the depth axis, increasing positive numbers on the axis show the corresponding increasing depths within the mat, whereas increasing negative numbers show the corresponding increasing distance from the matwater interface in the overlying water.

consumption at the lower boundary of the oxic zone, a zone of low $\mathrm{O}_{2}$ production and a (broad) zone of low $\mathrm{O}_{2}$ consumption were calculated. The calculated areal rates of net $\mathrm{O}_{2}$ production and consumption amounted to $0.658 \mathrm{nmol} \mathrm{O}_{2}$ $\mathrm{cm}^{-2} \mathrm{~s}^{-1}$ and $0.179 \mathrm{nmol} \mathrm{O}_{2} \mathrm{~cm}^{-2} \mathrm{~s}^{-1}$, resulting in a total net production rate of $0.479 \mathrm{nmol} \mathrm{O} \mathrm{cm}^{-2} \mathrm{~s}^{-1}$.

The depth distribution of net $\mathrm{O}_{2}$ production/consumption zones did not change when the average profile of $D_{s}$ and $D_{\text {app }}$ from the NMR measurements (Fig. 5D,F) was used for profile analysis (data not shown), only the magnitude of calculated rates (Table 2).

Both the depth distribution of $\mathrm{O}_{2}$ production/consumption zones and the magnitude of the calculated rates changed when the depth profiles of $D_{s}$ and $D_{\text {app }}$ from two different 
Table 1. Outcome of oxygen profile analysis (April mat) with a numerical procedure (Berg et al. 1998) using (1) a constant diffusivity (const. $D_{\text {app }}$ ), (2) the average profile of $D_{s}$ from the NMR measurements and a constant porosity of 0.9 (avg. $D_{s}$ ), (3) the average (NMR) profile of diffusivity (avg. $D_{\text {app }}$ ), (4) the (NMR) profile of $D_{s}$ from two different positions in the mat and a constant porosity of 0.9 [ $D_{s}$ (pos. 1), $D_{s}$ (pos. 2)], and (5) the (NMR) profile of $D_{\text {app }}$ from the two different positions $\left[D_{\text {app }}\right.$ (pos. 1), $D_{\text {app }}$ (pos. 2)]. Abbreviations: calc. (calculated), NP (net production), NC (net consumption), and TNP (total net production).

\begin{tabular}{|c|c|c|c|c|c|}
\hline \multirow{2}{*}{$\begin{array}{l}\text { Oxygen } \\
\text { profile } \\
\text { analysis } \\
\text { with }\end{array}$} & \multirow{2}{*}{$\begin{array}{c}\text { No. } \\
\text { of } \\
\text { calc. } \\
\text { zones }\end{array}$} & \multicolumn{3}{|c|}{$\begin{array}{l}\text { Magnitude of calculated rates } \\
\left(\mathrm{nmol} \mathrm{O} \mathrm{cm}^{-2} \mathrm{~s}^{-1}\right)\end{array}$} & \multirow[t]{2}{*}{$\begin{array}{l}\text { Comparison } \\
\text { of TNP rates } \\
\text { to the rate } \\
\text { calculated } \\
\text { using const. } \\
D_{\text {app }}(*) \\
\text { (in } \% \text { of } * \text { ) }\end{array}$} \\
\hline & & NP & $\mathrm{NC}$ & TNP & \\
\hline $\begin{array}{l}\text { Const. } D_{\text {app }} \\
\text { nat }\end{array}$ & 6 & 0.347 & 0.121 & $0.226(*)$ & - \\
\hline Avg. $D_{s}$ & 6 & 0.327 & 0.100 & 0.227 & $+0.4 \%$ \\
\hline Avg. $D_{\text {app }}$ & 6 & 0.241 & 0.084 & 0.157 & $-31 \%$ \\
\hline$D_{s}($ pos. 1$)$ & 6 & 0.236 & 0.110 & 0.126 & $-44 \%$ \\
\hline$D_{\text {app }}($ pos. 1$)$ & 6 & 0.139 & 0.076 & 0.063 & $-72 \%$ \\
\hline$D_{s}($ pos. 2$)$ & 6 & 0.292 & 0.133 & 0.159 & $-30 \%$ \\
\hline$D_{\text {app }}($ pos. 2) & 6 & 0.206 & 0.098 & 0.108 & $-52 \%$ \\
\hline
\end{tabular}

positions in the mat (Fig. 4) were used for profile analysis (Table 2, Fig. 8).

\section{Discussion}

We present the first application of ${ }^{1} \mathrm{H}-\mathrm{NMR}$ imaging to determine diffusion characteristics of microbial mats. Both the vertical depth distribution and an estimate of the horizontal variability of the $\mathrm{H}_{2} \mathrm{O}$ diffusion coefficient and water density within the mat could be obtained with this technique. In the following we discuss the current limitations of the technique together with the implications of our results for the analysis of microprofiles.

Water density-The diffusion coefficients measured with pulsed field gradient NMR correspond to the tortuosity corrected $\mathrm{H}_{2} \mathrm{O}$ diffusion coefficient, i.e., $D_{s}$, since only the average displacement of the ensembles and not their magnitude is monitored (Beuling et al. 1998). To obtain information about the apparent diffusivity ( $D_{\text {app }}$ ) in mats, it is therefore necessary to additionally determine the porosity of the mat, preferably at the same high spatial resolution.

We used the normalized mat water density determined by multiecho imaging as an estimate of the mat porosity. The images of the amplitude $A_{0}$ represent the proton $\left({ }^{1} \mathrm{H}\right)$ density, i.e., the amount of protons per pixel of defined volume. The normalized water density would directly reflect the porosity if only extracellular water contributed to the observed NMR signal. The measured water density may include, however, not only extracellular, but also intracellular water, representing an aqueous phase that is not completely accessible for diffusive solute transport within mats. Although intracellular water may have shorter $T_{2}$ relaxation times than extracellular water, as measured in granular sludge from waste water re-

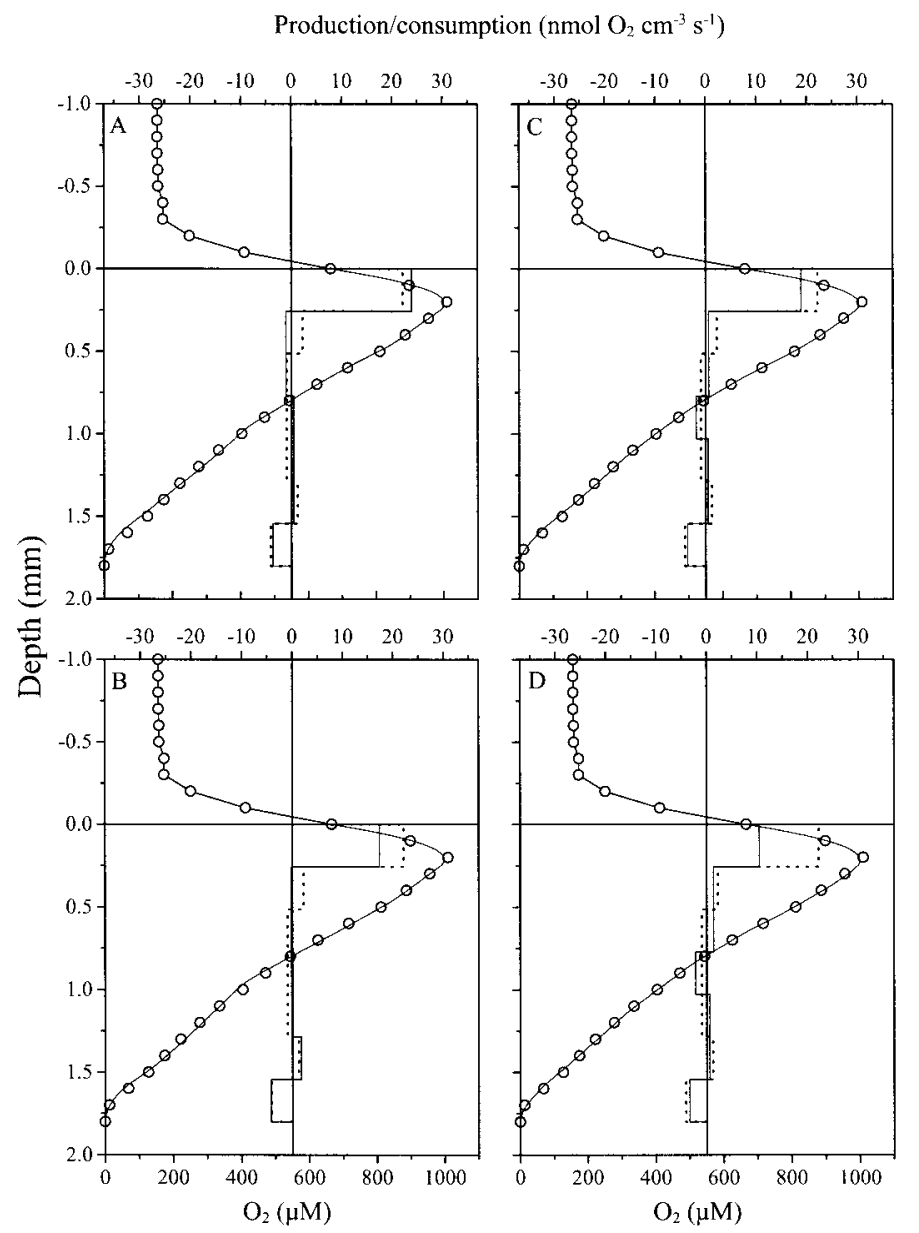

Fig. 8. Calculated depth profile of $\mathrm{O}_{2}$ production/consumption zones (bars) if (A) the $D_{s}$ profile and (B) the $D_{\text {app }}$ profile at the first position (Fig. 4A,C), and (C) the $D_{s}$ profile and (D) the $D_{\text {app }}$ profile at the second position (Fig. $4 \mathrm{D}, \mathrm{F}$ ) in the November mat was used for profile analysis (see text). Since $D_{s}$ and, therefore, also $D_{\text {app }}$ at the mat surface could not be determined from the NMR measurements (Fig. 4), the values from the next following depth were used for the mat surface in profile analysis. The dotted bars indicate the calculated reaction zones if a constant diffusivity is assumed. Open circles show the measured $\mathrm{O}_{2}$ concentration profile. The line graphs indicate the fitted profiles calculated by the numerical procedure (Berg et al. 1998). The mat surface is located at depth 0 on the depth axis, increasing positive numbers on the axis show the corresponding increasing depths within the mat, whereas increasing negative numbers show the corresponding increasing distance from the mat-water interface in the overlying water.

actors (Lens et al. 1997, 1999) and artificial biofilms (Beuling et al. 1998), and thus may not have significantly contributed to the measured NMR signal, its contribution to the amplitude images needs further investigation. A distinction between the fractions of extracellular and intracellular water would be possible on the basis of restricted diffusion and relaxation phenomena (Potter et al. 1996). Furthermore, protons from, e.g., lipids and sugars can also contribute to the signal (Edzes et al. 1998), which could cause a slight overestimation of the mat water density, especially in the upper mat layers with high microbial population densities. These 
Table 2. Outcome of oxygen profile analysis (November mat) with a numerical procedure (Berg et al. 1998) using (1) a constant diffusivity (const. $D_{\text {app }}$ ), (2) the average profile of $D_{s}$ from the NMR measurements and a constant porosity of 0.9 (avg. $D_{s}$ ), (3) the average (NMR) profile of diffusivity (avg. $D_{\text {app }}$ ), (4) the (NMR) profile of $D_{s}$ from two different positions in the mat and a constant porosity of 0.9 [ $D_{s}$ (pos. 1), $D_{s}$ (pos. 2)], and (5) the (NMR) profile of $D_{\text {app }}$ from the two different positions $\left[D_{\text {app }}\right.$ (pos. 1), $D_{\text {app }}$ (pos. 2)]. Abbreviations: calc. (calculated), NP (net production), NC (net consumption), and TNP (total net production).

\begin{tabular}{|c|c|c|c|c|c|}
\hline \multirow{2}{*}{$\begin{array}{l}\text { Oxygen } \\
\text { profile } \\
\text { analysis } \\
\text { with }\end{array}$} & \multirow{2}{*}{$\begin{array}{l}\text { No. } \\
\text { of } \\
\text { calc. } \\
\text { zones }\end{array}$} & \multicolumn{3}{|c|}{$\begin{array}{l}\text { Magnitude of calculated rates } \\
\qquad\left(\mathrm{nmol} \mathrm{O}_{2} \mathrm{~cm}^{-2} \mathrm{~s}^{-1}\right)\end{array}$} & \multirow[t]{2}{*}{$\begin{array}{l}\text { Comparison } \\
\text { of TNP rates } \\
\text { to the rate } \\
\text { calculated } \\
\text { using const. } \\
D_{\text {app }}(*) \\
\text { (in } \% \text { of } * \text { ) }\end{array}$} \\
\hline & & NP & $\mathrm{NC}$ & TNP & \\
\hline Const. $D_{\text {app }}$ & 5 & 0.658 & 0.179 & $0.479(*)$ & - \\
\hline Avg. $D_{s}$ & 5 & 0.558 & 0.157 & 0.401 & $-16 \%$ \\
\hline Avg. $D_{\text {app }}$ & 5 & 0.403 & 0.129 & 0.274 & $-43 \%$ \\
\hline$D_{s}($ pos. 1$)$ & 4 & 0.648 & 0.147 & 0.501 & $+5 \%$ \\
\hline$D_{\text {app }}($ pos. 1$)$ & 4 & 0.489 & 0.123 & 0.366 & $-24 \%$ \\
\hline$D_{s}($ pos. 2) & 5 & 0.544 & 0.140 & 0.404 & $-16 \%$ \\
\hline$D_{\text {app }}($ pos. 2) & 5 & 0.368 & 0.143 & 0.225 & $-53 \%$ \\
\hline
\end{tabular}

factors could have led to an overestimation of the mat porosity. The error made by using the normalized water density as an estimate of the porosity is, however, difficult to estimate.

Water diffusion coefficients-Non-spatially resolved pulsed field gradient NMR was applied by Beuling et al. (1998) to determine the diffusive properties of biofilms. These authors showed that the diffusion coefficients of water measured with PFG NMR agreed with reported literature data, and that the water diffusion coefficients measured in alginate matrices with PFG NMR corresponded with literature data of normalized diffusion coefficients of, e.g., $\mathrm{O}_{2}$. It was also shown that in artificial biofilms the water diffusion coefficient decreased with increasing volume fraction of bacteria and that measured diffusion coefficients in natural biofilms compared well with those estimated from the physical biofilm characteristics by use of models.

However, the diffusion of water may not be completely representative for the diffusion of solutes in microbial mats. Whereas the effect of polymers on the diffusion of different solutes should be comparable, the permeability of cells for the solutes may vary. Cells are generally permeable for water, but if the short time period for diffusion labeling and the restricted and slow diffusion of water within bacterial cells is considered (see also Beuling et al. 1998), this diffusional flux of water through the cells may be of minor importance. Although gases may passively diffuse into cells, there seem to exist significant differences between bacteria concerning the gas permeability (Beuling 1998). Like the diffusion of water, $\mathrm{O}_{2}$ diffusion may also be affected significantly by high densities of microbial cells due to the different $\mathrm{O}_{2}$ permeability of microbial cells and the low $\mathrm{O}_{2}$ diffusion coefficient within cells permeable for $\mathrm{O}_{2}$ (Beuling 1998).
NMR and microsensor diffusivity measurements-We obtained similar results with a diffusivity microsensor using an inert tracer gas and NMR imaging in comparable mats. This indicates that the diffusion of water and gases seems to be similarly affected in microbial mats. However, the apparent diffusivity profiles exhibited some differences between the microsensor and NMR data in the upper $2 \mathrm{~mm}$ (Fig. 6). The diffusivity at the mat surface bears the highest uncertainty with both methods due to the uncertainty in defining the surface. Also, if the principle of the diffusivity microsensor is considered (Revsbech et al. 1998), the diffusion of the tracer gas away from the sensor tip at the surface should be affected by the adjacent overlying water and was therefore probably overestimated. Some differences could also arise due to the fact that (a) we compare a noninvasive method with an invasive method, (b) we compare profiles of apparent diffusivity measured in different (but comparable) mat samples, and (c) the microsensor measures apparent gas diffusivity as a function of mat porosity and tortuosity $\left(\phi D_{s}\right)$, whereas the apparent water diffusivities were estimated as the product of the water density and $D_{s}$ determined with NMR. Nevertheless, apparent diffusivities in the depth interval from 2 to $4 \mathrm{~mm}$ were rather similar (Fig. 6), indicating that the error made due to the above mentioned points may not be severe.

Oxygen, water density, and diffusion coefficient in Solar Lake microbial mats-The structure and microbial composition of the April and the November mats differed in the 1to 3-mm thick surface layer, and this led also to pronounced differences in $\mathrm{O}_{2}$ distribution in the mats (Figs. 7, 8). Although measured at lower surface irradiances, $\mathrm{O}_{2}$ penetrated deeper into the April mat than the November mat. The $\mathrm{O}_{2}$ profile in the April mat showed the presence of a broad photosynthetic active zone with a subsurface photosynthetic zone in a dense layer dominated by filamentous cyanobacteria. A prerequisite for this is a deep light penetration, probably facilitated by an accumulation of exopolymers in the gelatinous and partly translucent surface layer of the mat. The distinct $\mathrm{O}_{2}$ peak in the November mat indicates intense photosynthesis only in the surface layer dominated by filamentous cyanobacteria.

The seasonal changes of the cyanobacterial mats in the shallow part of Solar Lake, i.e., the dominance of filamentous cyanobacteria at the mat surface in winter and of unicellular cyanobacteria and diatoms in summer, were already described by Krumbein et al. (1977). A crucial parameter for this seasonality seems to be the sensitivity of filamentous cyanobacteria to photooxidative stress (Krumbein et al. 1977) and may partly be caused by migration of filamentous cyanobacteria in response to UV and the intensity of visible light (Bebout and Garcia-Pichel 1995).

In both mats, an increase of the average water density below the surface layer was found (Fig. 5). The high water density in this layer could have been due to an enrichment of exopolysaccharides (exopolymers), which can contain significant amounts of water (Christensen and Characklis 1990; Decho 1994). Exopolymers may include slimes produced by unicellular cyanobacteria and diatoms and the sheaths of filamentous cyanobacteria, like the sheathed bundles of $M$. 
chthonoplastes, which can reach a thickness of up to $15 \mu \mathrm{m}$ (Jørgensen et al. 1983). The decrease of the water density in deeper parts of the mats indicates an increased compaction of the mat.

In the subsurface layer of high water density, the average $\mathrm{H}_{2} \mathrm{O}$ diffusion coefficient $D_{s}$ also showed a peak at approximately the same depth in both mats (Fig. 5). We speculate that an increased amount of exopolymers and probably also lower cell densities could have led to a less pronounced hindrance of diffusion in that layer. The variability of $D_{s}$ at increasing depth was influenced by the distinct lamination pattern present in the mats due to overgrowth and preservation of photic layers from earlier years.

The observed variability of $D_{s}$ and water density, especially in the upper part of the mats (Fig. 5), indicates a vertical and horizontal heterogeneous distribution of exopolymers and microbial cell densities. Thus, in such complex and heterogeneous matrices, the apparent diffusivity has to be determined with fine-scale techniques like NMR imaging or diffusivity microsensors. Our results on the diffusion characteristics of microbial mats are in accordance with findings of high-resolution studies on metal (Davison et al. 1997) and $\mathrm{O}_{2}$ (Glud et al. 1999) distributions in microbial mats, further indicating that microbial mats are characterized by a pronounced vertical and horizontal microscale heterogeneity concerning their microstructure and the fine-scale distribution of biogeochemical processes.

Microprofile analysis-The diffusive properties of the mats obtained from the NMR measurements were used to estimate their effect on the analysis of measured $\mathrm{O}_{2}$ concentration profiles and the calculation of net $\mathrm{O}_{2}$ production rates. The obtained results demonstrate how heterogeneity of solute diffusivity can affect profile analysis. Uncertainties of this approach are (1) the estimates of $D_{\text {app }}$ bear a potential error (see above), (2) some differences concerning the diffusivity of water and $\mathrm{O}_{2}$ may occur in the microbial mats, and (3) the $\mathrm{O}_{2}$ concentration profiles were measured at a certain position in the mats and the diffusive properties of these positions may have differed from the $D_{s}$ and $D_{\text {app }}$ profiles used for the $\mathrm{O}_{2}$ profile analysis. Since microsensor measurements are point measurements, we not only used the average $D_{s}$ and average $D_{\text {app }}$ profiles in the analysis, but also profiles of $D_{s}$ and $D_{\text {app }}$ selected from two different positions in the mats. For the interpretation of the $\mathrm{O}_{2}$ profiles, the horizontally averaged $D_{\text {app }}$ profile will result in an underestimation, whereas the distinct profiles of $D_{\text {app }}$ extracted from different positions will overestimate the effect of vertical variability of $D_{\text {app }}$ on profile analysis.

The obtained results clearly indicate the importance of considering the heterogeneity of solute diffusivity for the interpretation of measured concentration profiles. When profile analysis was performed with the measured diffusivities and compared to the results obtained using a constant diffusivity, calculated total net $\mathrm{O}_{2}$ production rates showed maximal variations of more than $50 \%$. Furthermore, the solute diffusivity may not only affect the magnitude of calculated rates, but also the depth distribution of calculated activity zones (Figs. 7, 8). In all analyses, the effect of $D_{\text {app }}$ was much more pronounced than the effect of $D_{s}$, pointing to the necessity of fine-scale determination of both $D_{s}$ and porosity if the apparent diffusivity is not measured directly.

Recently developed techniques for mapping two-dimensional solute distributions have also demonstrated pronounced heterogeneity in the distribution of oxygen, respiration, and photosynthesis within microbial mats (Glud et al. 1999). Their analysis was, however, based on the assumption of constant diffusivity throughout the mat. Used in combination, the NMR and oxygen imaging seem ideal tools for future studies of oxygen dynamics in sediments, microbial mats, and biofilms.

\section{Conclusions}

NMR imaging is a powerful new tool to investigate the diffusional properties of heterogeneous systems like microbial mats and sediments. The Solar Lake microbial mats exhibited a strong horizontal and vertical variability of water diffusion coefficient and water density due to the heterogeneous distribution of polymers and cell densities within the mats. The profile of estimated apparent water diffusivity obtained with NMR imaging and of apparent $\mathrm{O}_{2}$ diffusivity measured with a diffusivity microsensor in a comparable mat were rather similar, indicating that the diffusivity of gases and water was affected in the same way by the structure and composition of the microbial mats. The measured variability of apparent diffusivity affected the outcome of $\mathrm{O}_{2}$ concentration profile analysis significantly. It is thus important to take spatial heterogeneity of diffusive properties into account when interpreting solute concentration profiles measured with microsensors in natural microbial mats and sediments.

\section{References}

AmanN, R., AND M. KüHL. 1998. In situ methods for assessment of microorganisms and their activities. Current Opinions in Microbiology 1: 352-358.

Bebout, B. M., ANd F. Garcia-Pichel. 1995. UV B-induced vertical migrations of cyanobacteria in a microbial mat. Appl. Environ. Microbiol. 61: 4215-4222.

Berg, P., N. RisgaArd-Petersen, and S. RysgaArd. 1998. Interpretation of measured concentration profiles in sediment pore water. Limnol. Oceanogr. 43: 1500-1510.

Berner, R. A. 1980. Early diagenesis. Princeton Univ. Press.

Beuling, E. E. 1998. Mass transfer properties of biofilms. Ph.D. thesis. Univ. Amsterdam.

- D. van Dusschoten, P. Lens, J. C. van den Heuvel, H. VAN As, AND S. P. P. OTtENGRAF. 1998. Characterization of the diffusive properties of biofilms using pulsed field gradientnuclear magnetic resonance. Biotechnol. Bioeng. 60: 283-291.

Boudreau, B. P. 1997. Diagenetic models and their implementation. Springer.

Broecker, W. S., And T.-H. Peng. 1974. Gas exchange rates between air and sea. Tellus 26: 21-35.

Christensen, B. E., And W. G. Characklis. 1990. Physical and chemical properties of biofilms, p. 93-130. In W. G. Characklis and K. C. Marshall [eds.], Biofilms. Wiley.

Cronenberg, C. C. H., And J. C. VAn den Heuvel. 1991. Determination of glucose diffusion coefficients in biofilms with micro-electrodes. Biosens. Bioelectron. 6: 255-262.

Davison, W., G. R. Fones, and G. W. Grime. 1997. Dissolved 
metals in surface sediment and a microbial mat at $100-\mu \mathrm{m}$ resolution. Nature 387: 885-888.

DE BeER, D., P. Stoodley, ANd Z. Lewandowski. 1997. Measurement of local diffusion coefficients in biofilms by microinjection and confocal microscopy. Biotechnol. Bioeng. 53: 151158.

Decho, A. W. 1994. Exopolymers in microbial mats: Assessing their adaptive roles, p. 215-219. In L. J. Stal and P. Caumette [eds.], Microbial mats: Structure, development and environmental significance. NATO ASI Series G, vol. 35. Springer.

DuUrsma, E. K., AND C. J. BosCH. 1970. Theoretical, experimental and field studies concerning diffusion of radioisotopes in sediments and suspended particles of the sea. Part B: Methods and experiments. Neth. J. Sea Res. 4: 395-469.

Edzes, H. T., D. van Dusschoten, And H. Van As. 1998. Quantitative $T_{2}$ imaging of plant tissues by means of multi-echo MRI microscopy. Magnetic Resonance Imaging 16: 185-196.

EPPING, E. H. G., AND B. B. JøRGENSEN. 1996. Light-enhanced oxygen respiration in benthic phototrophic communities. Mar. Ecol. Prog. Ser. 139: 193-203.

Garcia-Pichel, F., U. Nübel, And G. Muyzer. 1998. The phylogeny of unicellular, extremely halotolerant cyanobacteria. Arch. Microbiol. 169: 469-482.

Glud, R. N., K. Jensen, And N. P. Revsbech. 1995. Diffusivity in surficial sediments and benthic mats determined by use of a combined $\mathrm{N}_{2} \mathrm{O}-\mathrm{O}_{2}$ microsensor. Geochim. Cosmochim. Acta 59: 231-237.

- M. KüHL, O. KoHLS, AND N. B. Ramsing. 1999. Heterogeneity of oxygen production and consumption in a photosynthetic microbial mat as studied by planar optodes. J. Phycol. 35: $270-279$.

Jeroschewski, P., C. Steuckart, AND M. KÜHL. 1996. An amperometric microsensor for the determination of $\mathrm{H}_{2} \mathrm{~S}$ in aquatic environments. Anal. Chem. 68: 4351-4357.

Jørgensen, B. B., And Y. CohEn. 1977. Solar Lake (Sinai). 5. The sulfur cycle of the benthic cyanobacterial mats. Limnol. Oceanogr. 22: 657-666.

-, N. P. Revsbech, T. H. Blackburn, and Y. Cohen. 1979. Diurnal cycle of oxygen and sulfide microgradients and microbial photosynthesis in a cyanobacterial mat sediment. Appl. Environ. Microbiol. 38: 46-58.

,-- AND Y. COHEN. 1983. Photosynthesis and structure of benthic microbial mats: Microelectrode and SEM studies of four cyanobacterial communities. Limnol. Oceanogr. 28: 10751093.

Krumbein, W. E., Y. Cohen, And M. Shilo. 1977. Solar Lake (Sinai). 4. Stromatolitic cyanobacterial mats. Limnol. Oceanogr. 22: 635-656.

KüHl, M., C. Steuckart, G. Eickert, and P. Jeroschewski. 1998. A $\mathrm{H}_{2} \mathrm{~S}$ microsensor for profiling biofilms and sediments: Application in an acidic lake sediment. Aquat. Microb. Ecol. 15: 201-209.

Lens, P., L. H. Pol, G. Lettinga, And H. Van As. 1997. Use of ${ }^{1} \mathrm{H}$ NMR to study transport processes in sulfidogenic granular sludge. Water Sci. Technol. 36: 157-163

—, F. Vergeldt, G. Lettinga, AND H. VAN As. 1999. ${ }^{1} \mathrm{H}$ NMR characterisation of the diffusional properties of methanogenic granular sludge. Water Sci. Technol. 39: 187-194

LI, Y.-H., AND S. GREgORY. 1974. Diffusion of ions in sea water and in deep-sea sediments. Geochim. Cosmochim. Acta 38: 703-714.

Lorenzen, J., R. N. Glud, AND N. P. Revsbech. 1995. Impact of microsensor-caused changes in diffusive boundary layer thickness on $\mathrm{O}_{2}$ profiles and photosynthetic rates in benthic com- munities of microorganisms. Mar. Ecol. Prog. Ser. 119: 237_ 241.

Moonen, C. T. W., P. C. M. van ZiJl, J. A. Frank, D. Le Bihan, AND E. D. BECKER. 1990. Functional magnetic resonance imaging in medicine and physiology. Science 250: 53-61.

MoRRIS, P. G. 1986. Nuclear magnetic resonance imaging in medicine and biology. Clarendon.

Nielsen, L. P., P. B. Christensen, N. P. Revisbech, and J. SøRENSEN. 1990. Denitrification and oxygen respiration in biofilms studied with a microsensor for nitrous oxide and oxygen. Microb. Ecol. 19: 63-72.

Potter, K., R. L. Kleinberg, F. J. Brockman, and E. W. MCFARLAND. 1996. Assay for bacteria in porous media by diffusion-weighted NMR. Journal of Magnetic Resonance B 113: 9-15.

Press, W. H., S. A. Teukolsky, W. T. Vetterling, and B. P. FlanNery. 1992. Numerical recipes in C. Cambridge Univ. Press.

Rasmussen, H., AND B. B. JøRGENSEN. 1992. Microelectrode studies of seasonal oxygen uptake in a coastal sediment: Role of molecular diffusion. Mar. Ecol. Prog. Ser. 81: 289-303.

REVSBECH, N. P. 1989a. Diffusion characteristics of microbial communities determined by use of oxygen microsensors. J. Microbiol. Methods 9: 111-122.

$1989 b$. An oxygen microelectrode with a guard cathode. Limnol. Oceanogr. 34: 474-478.

, AND B. B. JøRGENSEN. 1986. Microelectrodes: Their use in microbial ecology. Adv. Microb. Ecol. 9: 293-352.

- B. MADSEN, AND B. B. JøRGENSEN. 1986. Oxygen production and consumption in sediments determined at high spatial resolution by computer simulation of oxygen microelectrode data. Limnol. Oceanogr. 31: 293-304.

, L. P. Nielsen, AND N. B. Ramsing. 1998. A novel microsensor for determination of apparent diffusivity in sediments. Limnol. Oceanogr. 43: 986-992.

Scheenen, T. W. J., D. van Dusschoten, P. A. DE Jager, AND H. VAN As. 1998. Fast spatially resolved displacement imaging in (bio)systems, p. 482-486. In P. Blümler, B. Blümich, R. Botto, and E. Fukushima [eds.], Spatially resolved magnetic resonance. Wiley.

Sherwood, J. E., F. Stagnitti, M. J. Kokkinn, and W. D. WiLLIAMS. 1991. Dissolved oxygen concentrations in hypersaline waters. Limnol. Oceanogr. 36: 235-250.

StejsKal, E. O., AND J. E. TANNER. 1965. Spin diffusion measurements: Spin echoes in the presence of a time-dependent field gradient. J. Chem. Phys. 42: 288-292.

Ullman, W. J., AND R. C. Aller. 1982. Diffusion coefficients in nearshore marine sediments. Limnol. Oceanogr. 27: 552-556.

VAN As, H., AND D. VAN DUSSChOTEN. 1997. NMR methods for imaging of transport processes in micro-porous systems. Geoderma 80: 389-403.

van Dusschoten, D., C. T. W. Moonen, P. A. DE Jager, and H. VAN As. 1996. Unraveling diffusion constants in biological tissue by combining Carr-Purcell-Meiboom-Gill Imaging and pulsed field gradient NMR. Magnetic Resonance in Medicine 36: $907-913$.

WiElAND, A., AND M. KÜHL. 2000a. Short-term temperature effects on oxygen and sulfide cycling in a hypersaline cyanobacterial mat (Solar Lake, Egypt). Mar. Ecol. Prog. Ser. 196: 87-102. , AND - 2000b. Irradiance and temperature regulation of oxygenic photosynthesis and $\mathrm{O}_{2}$ consumption in a hypersaline cyanobacterial mat (Solar Lake, Egypt). Mar. Biol. 137: $71-85$.

Received: 6 April 2000 Accepted: 19 October 2000 Amended: 1 December 2000 